Кафиятуллина Юлия Насиховна ассистент, ФГБОУ ВО «Государственный университет управления», г. Москва e-mail: ule4ka.91@mail.ru

Панфилова Елена Евгеньевна канд. экон. наук, ФГБОУ ВО «Государственный университет управления», г. Москва e-mail: helena_panfilova@mail.ru
Kafiyatullina Yuliya

Assistant, State University

of Management, Moscow

e-mail: ule4ka.91@mail.ru

\section{Panfilova Elena}

Candidate of Economic Sciences, State University of Management, Moscow e-mail: helena_panfilova@mail.ru

\section{РОЛЬ РАЗВИТИЯ КОНЦЕПЦИЙ ОПЕРАЦИОННОГО МЕНЕДЖМЕНТА В УПРАВЛЕНИИ ИННОВАЦИЯМИ}

\begin{abstract}
Аннотация. Рассмотрена роль развития концепций операционного менеджмента с иеелью обеспечить системную поддержку в инновационной деятельности организации. Отмечено, что каждая концепция является организаџионной инновацией для реализации операционной деятельности, каждая последующая конщепция не противоречит предыдущей - это делает возможным одновременное применение нескольких с иелью повышения эффективности функиионирования организачии. Сделан вывод, что комплексное применение концепций позволяет создать организационную среду для создания и внедрения инноваций на постоянной основе. Объединение элементов различных концепций, методических рекомендаций операционного менеджмента и управления инновациями находит отражение в рамках интеграционного подхода на базе цицрровых технологий.
\end{abstract}

Ключевые слова: интеграционный подход, концепция, операционный менеджмент, управление инновациями, цифровые технологии.

\section{THE ROLE OF THE DEVELOPMENT OF OPERATIONAL MANAGEMENT CONCEPTS IN THE INNOVATIONS MANAGEMENT}

\begin{abstract}
The role of the development of operational management concepts in order to provide systematic support for the organization's innovation activities has been considered. It has noticed, that each concept is an organizational innovation for the implementation of operational activities, with each subsequent does not contradict the previous one, which makes possible simultaneous application of several in order to improve the efficiency of the organization. It has concluded, that the integrated application concept allows you to create an organizational environment for creating and implementing innovations on an ongoing basis. The combination of elements of different concepts, methodological recommendations of operational management and innovation management is reflected in the integration approach based on digital technologies.
\end{abstract}

Keywords: integration approach, concept, operational management, innovation management, digital technologies.

Операционный менеджмент включает комплекс действий по преобразованию любых видов ресурсов для создания продукции, оказания услуг, выполнения работ. Улучшение работы операционной системы в организациях было связано с необходимостью повышения ее производительности и эффективности. Целевое предназначение операционного менеджмента ранее ограничивалось обеспечением роста результативности производственной деятельности. Развитие концепций операционного менеджмента увеличило спектр организационных задач, подлежащих решению. В результате эволюция концепций способствовала эффективному созданию и последующему внедрению различного рода инноваций. Операционный менеджмент в организации одновременно является одним из источников идей, лежащих в основе инноваций и системой, в рамках которой инновации реализуются.

В условиях инновационной экономики операционный менеджмент должен обеспечивать возможность реализации сотрудниками своих идей, стимулировать их творческую активность и создавать условия для практического внедрения новшеств. В настоящее время инструментарий операционного менеджмента очень развит, что безусловно может способствовать повышению инновационной активности организаций в России. В 2016 г. в целом по промышленному производству инновационная активность составила 10,5 \%, в основном организации осуществляют технологические инновации. В строительстве инновационная активность

(C) Кафиятуллина Ю.Н., Панфилова Е.Е., 2018. Статья доступна по лицензии Creative Commons «Attribution» («Атрибуция») 4.0. всемирная (http://creativecommons.org/licenses/by/4.0/).

The Author(s), 2018. This is an open access article under the CC BY 4.0 license (http://creativecommons.org/licenses/by/4.0/).

(c) (i) 
составляет всего 1,5 \%, при этом организации в равной степени осуществляют технологические и организационные инновации, показатель в 2016 г. для двух видов инноваций составил 1,1\%. Удельный вес организаций, реализующих технологические инновации, в общем числе организаций промышленного производства в России в 2016 г. составил 9,2 \%, в то время как в Швейцарии данный показатель составил $60,2 \%$, в Бельгии $-59,7 \%$, в Германии - 58,9\%. Такое существенное отставание России от развитых стран Европы подтверждают выводы многих ученых, которые говорят о наличии в нашей стране структурных проблем в ряде отраслей народного хозяйства и в экономике в целом. Перед отечественными организациями стоит вопрос: как наилучшим образом организовать свою деятельность, чтобы в кротчайшие сроки повысить свою инновационную активность, которая обеспечивает долгосрочное устойчивое функционирование и конкурентоспособность?

Основные международные документы по управлению инновациями созданы в рамках международной деятельности ЮНИДО - организации объединенных наций по промышленному развитию, Организации Экономического сотрудничества и развития. Руководство ОСЛО, руководство Фраскати, руководство по патентованию содержат международные методологические рекомендации и стандарты по управлению инновациями.

Для операционного менеджмента инновации могут представлять собой единичные изменения в процессе управления операциями (процессные инновации), охватывать отдельные функциональные зоны или распространяться в целом на всю организацию. Каждую вновь появляющуюся концепцию операционного менеджмента можно рассматривать как инновацию.

Использование научного подхода Ф. Тейлора в управлении, его принципов является примером организационной инновации. Затем, Тойота (Toyota production system) в 1950-е гг. XX в. организует свою операционную деятельность на основе концепции «бережливого производства», автором которой считается Т. Оно. Цель Toyota production system - это сокращение любых потерь, способствующих увеличению затрат, не создающих добавленной ценности. В операционной деятельности выделяют операции, которые не добавляют ценность для потребителя, но при этом становятся источником формирования затрат. В концепции бережливого производства они получили название «потери». Выделяют следующие типы потерь: перепроизводство, ожидание, ненужная транспортировка, избыточная обработка, излишние запасы, ненужные движения, переделывание/дефекты, неэффективное использование интеллектуальных ресурсов [1; 7; 8].

Последовательная реализация мероприятий по устранению операций, приводящих к потерям, или максимальному сокращению времени на них находит отражение в уменьшении затрат на материальные ресурсы на единицу продукции, сокращении расходов по обслуживанию производственной деятельности, ликвидации потерь от брака и других непроизводительных расходов. Операционная деятельность Тойота основывается на идеологии кайзен (яп. kaizen), в основе которой лежит стремление совершенствованию своей деятельности путем реализации постепенных непрерывных улучшений, которые в свою очередь могут приводить к организационным, технологическим или маркетинговым инновациям $[1 ; 7 ; 8]$.

Изначально управление инновациями и концепции операционного менеджмента не учитывали возрастающую конкуренцию на рынках, потребности и запросы потребителей, технологические изменения в отраслях и структурные сдвиги в экономике. После понимания необходимости повышения производительности, руководители организаций осознали потребность в повышении качества производственной деятельности выпускаемых продуктов и оказываемых услуг. Создание и сохранение рыночной позиции обеспечивалось через управление качеством. Метод статистического контроля процессов У. Шухарта (англ. statistical process control), метод шести сигм (англ. six sigma) были созданы для управления качеством. Актуальными остаются следующие системы управления качества: серия международных стандартов ИСО 9000 (ISO 9000) и методология всеобщего контроля качества (англ. total quality management, TQM). Концепция TQM является организационной инновацией, но не является методом управления инновациями. Такие организационные инновации, как системы управления качеством позволяют системно улучшать операционную деятельность организации через нахождение слабых мест и последующее их устранение $[1 ; 8]$.

В настоящие время остается актуальной проблема поиска путей организации производства и изготовления продукции в минимальные сроки, соответствующего качества и при оптимальных затратах. Создание и обоснование применения интеграционного подхода представляется целесообразным для решения данной проблемы. Интеграционный подход, учитывающий современное положение организаций, должен 
содержать гибкий механизм, позволяющий объединить элементы концепций операционного менеджмента и концепций, методических рекомендаций, стандартов управления инновациями с широким применением цифровых технологий.

Важным шагом в развитии концепций операционного менеджмента стало восприятие инноваций как реакции на изменения во внешней среде, которые в свою очередь инициируют изменения в организациях. В рамках концепции шести сигм была создана методика design for six sigma. Design for six sigma предназначен для выявления, измерения, анализа, усовершенствования и контроля процесса операционной деятельности организаций. Design for six sigma стал широко использоваться для разработки новых продуктов, услуг.

Последующим этапом было создание направления изучения сложных систем, которая получила название «системная динамика». Данное направление основывается на переосмыслении понимания операционной деятельности, предлагает рассматривать ее как модель с использованием следующих элементов: уровни, потоки, функции решений (вентили), каналы информации, линии задержки (запаздывания), вспомогательные переменные. Рассмотрение операционной деятельности с позиций элементов, позволяет увидеть слабые места в организации. Управленческие решения, способные устранить слабые места, могут приобретать, например, вид организационной инновации. С другой стороны, через оценку состояния системы после изменения элементов модели можно сделать комплексный вывод о эффективности инновации. Данное направление позволяет рассматривать инновации в системе и может быть применено для продуктовых и процессных инноваций.

При проектировании элементов системы операционного менеджмента для управления инновациями целесообразна интеграция инструментов системной динамики с современными Agile-методами. В переводе agile означает «живой, подвижный», но чаще используется это понятие как «гибкий». В IT - отрасли термин появился после издания Agile Manifesto (манифест гибкой разработки программного обеспечения). С тех пор под «agile» понимают как набор гибких подходов, лежащих в основе разработки программного обеспечения.

Использование инструментария операционного менеджмента позволяет управлять инновациями в контексте всей своей деятельности. Практические весь инструментарий операционного менеджмента направлен на поддержку инноваций, начиная с формализованного финансового обоснования до повышения культуры обслуживания потребителей. Инструменты операционного менеджмента создают организационную среду для реализации управления потоком инноваций (Pipeline Innovation) [3; 4].

Поскольку в настоящее время ядром технологического уклада все еще продолжают быть цифровые технологии, стоит обратить внимание на ЕТОМ (англ. Enhanced Telecom Operations Map), которая является многоуровневой моделью бизнес-процессов управления производственной деятельностью или расширенной картой процессов деятельности организаций телекоммуникационной отрасли. Модель выступает как база для проведения анализа и проектирования бизнес-процессов в отрасли связи и ориентир при проектировании и разработке решений OSS/BSS [2].

Архитектура бизнес-процессов предназначена для поставщиков услуг связи и их контрагентов, реализующих свою деятельность в телекоммуникационной отрасли. Модель используется в разработке систем поддержки операционной деятельности для телекоммуникационных корпораций NGOSS [5; 6].

Интеграция существующих концепций операционного менеджмента и концепций, методических рекомендаций, стандартов управления инновациями с широким применением цифровых технологий и решений призвана объединить весь комплекс ресурсов, способностей и компетенций организации для обеспечения непрерывного внедрения результатов научно-технического прогресса с целью повышения ее устойчивого функционирования и конкурентоспособности.

\section{Библиографический список}

1. Баранчеев, В. П. и др. Управление инновациями: учебник для бакалавров / В. П. Баранчеев, Н. П. Масленникова, В. М. Мишин. - 2-е изд. - М.: Юрайт, 2015. - 711 с.

2. Кафиятуллина, Ю. Н. Обоснование актуальности применения интеграционного подхода к управлению затратами в системе операционного менеджмента. // Вестник университета (Государственный университет управления). - 2015. - № 9. - С. 179-183.

3. Кафиятуллина, Ю. Н. Проблемы роста эффективности инновационной деятельности организаций, осуществляющих технологические инновации / Ю. Н. Кафиятуллина, Г. П. Харчилава // Экономические системы. - 2017. - № 2. - С. 55-57. 
4. Панфилова, Е. Е. Развитие управления промышленными организациями в условиях инновационно-ориентированной экономики // Актуальные проблемы экономики и управления на предприятиях машиностроения, нефтяной и газовой промышленности в условиях инновационно-ориентированной экономики. - 2014. - Т. 1. - С. 254-260.

5. Панфилова, Е. Е. Управление интегрированными производственными процессами в организациях. // Экономика в промышленности. - 2014. - № 1. - С. 42-48.

6. Саломатин, Н. А. Организация и управление производством: учебное пособие. - М.: ГУУ, 2007. - 255 с.

7. Слак, Н. и др. Организация, планирование и проектирование производства. Операционный менеджмент. / Н. Слак, С. Чеймберс, Р. Джонстон. - М.: Инфра-М, 2013. - 816 с.

8. Глазьев, С. Ю. Великая цифровая революция: вызовы и перспективы развития для России XXI века [Электронный pecypc] // Официальный сайт. - Режим доступа: https:/www.glazev.ru/articles/6-jekonomika/54923-velikaja-tsifrovaja-revoljutsija-vyzovy-i-perspektivy-dlja-jekonomiki-i (дата обращения: 16.11.2018).

\section{References}

1. Barancheyev V. P., Maslennikova N. P., Mishin V. M. Upravleniye innovatsiyami: uchebnik dlya bakalavrov [Management of innovation: Textbook for bachelors], 2-ye izd. M.: Yurait, 2015, 711 p.

2. Kafiyatullina Yu. N. Obosnovaniye aktual'nosti primeneniya integratsionnogo podkhoda k upravleniyu zatratami v sisteme operatsionnogo menedzhmenta [Rationale for the relevance of the integration approach to cost management in the operational management system], Vestnik Universiteta (Gosudarstvennyi universitet upravleniya), 2015, I. 9, pp. 179-183.

3. Kafiyatullina Yu. N., Kharchilava G. P. Problemy rosta effektivnosti innovatsionnoi deyatel'nosti organizatsii, osushchestvlyayushchikh tekhnologicheskiye innovatsii [Problems of increasing the effectiveness of innovation activities of organizations implementing technological innovation], Ekonomicheskiye sistemy [Economic systems], 2017, I. 2, pp. 55-57.

4. Panfilova E. E. Razvitiye upravleniya promyshlennymi organizatsiyami v usloviyakh innovatsionno-oriyentirovannoi ekonomiki [The development of management of industrial organizations in an innovative-oriented economy], Aktual'nyye problemy ekonomiki i upravleniya na predpriyatiyakh mashinostroyeniya, neftyanoi i gazovoi promyshlennosti v usloviyakh innovatsionno-oriyentirovannoi ekonomiki [Actual problems of economics and management in enterprises of mechanical engineering, the oil and gas industry in an innovative-oriented economy], 2014, T. 1. pp. 254-260.

5. Panfilova E. E. Upravleniye integrirovannymi proizvodstvennymi protsessami v organizatsiyakh [Management of integrated production processes in organizations], Ekonomika v promyshlennosti [Russian Journal of Industrial Economics], 2014, I. 1, pp. 42-48.

6. Salomatin N. A. Organizatsiya i upravleniye proizvodstvom: uchebnoye posobiye [Organization and management of production: textbook], Moscow: GUU, 2007, 255 p.

7. Slak N. Organizatsiya, planirovaniye i proektirovaniye proizvodstva. Operatsionnyi menedzhment [Organization, planning and design of production. Operational management], M.: Infra-M, 2013, 816 p.

8. Glaz'yev S. YU. Velikaya tsifrovaya revolyutsiya: vyzovy i perspektivy razvitiya dlya Rossii XXI veka [The Great Digital Revolution: Challenges and Development Prospects for Russia in the 21st Century], Official sait. Available at: https://www.glazev. ru/articles/6-jekonomika/54923-velikaja-tsifrovaja-revoljutsija-vyzovy-i-perspektivy-dlja-jekonomiki-i (accessed 16.09.2018). 